\title{
A Literature Review on Interactions Between Stakeholders Through Accessibility Indicators Under Mobility as a Service Context
}

\author{
Hoang Duy PHAM $^{1}$ (D) . Tetsuo Shimizu ${ }^{1}$ (D) $\cdot$ Truong Van NGUYEN $^{2}$ (D)
}

Received: 4 June 2020 / Revised: 22 March 2021 / Accepted: 7 April 2021 / Published online: 10 May 2021

(c) The Author(s) 2021

\begin{abstract}
This study aims to explore accessibility indicators influencing the interactions between users, transport service providers (TSPs), and a platform operator, generating a conceptual framework for modeling these interactions under Mobility as a Service context. A systematic literature review was conducted to identify all studies focusing on indicators and modeling the interactions. There are limitations in integrating psychological indicators and dynamic pricing into the existing models. Moreover, there are gaps in considering monthly service packages, the efficiency of transport systems, and the perspectives of the TSPs for modeling the demand-supply interactions. The study ends with conclusions, discussions, and directions for further studies.
\end{abstract}

Keywords Mobility as a service $\cdot$ Accessibility indicators $\cdot$ Interactions $\cdot$ Stakeholders

\section{Introduction}

Mobility as a Service (MaaS) concept aims to integrate ondemand services, such as taxi, carsharing, bike-sharing, ridesharing, ride-hailing, and demand-responsive services with public transport services (PuT) to offer user-oriented mobility options, providing travel information, payment, and ticketing on and through a single platform [1]. MaaS is considered as a potential solution to enhance multimodal integration [2], economic, environmental, and social sustainability [3-5], and changes in travel behaviors and preferences [6]. Particularly, the Ubigo and Smile pilot presented a decrease in private car usage and an increase in the usage of carsharing and PuT [5, 7, 8]. Smile [9] and Whim [10] revealed that multimodal mobility was enhanced by combinations of bike-sharing with car-sharing and taxi with

Hoang Duy PHAM

phamduyhoang1984@gmail.com

Tetsuo Shimizu

t-sim@tmu.ac.jp

Truong Van NGUYEN

ngvtruong@utc.edu.vn

1 Department of Tourism Science, Tokyo Metropolitan University, Tokyo, Japan

2 Faculty of Transport and Economics, University of Transport and Communications, Hanoi, Vietnam
PuT. Storme et al. [11] studied travel patterns from Touring pilot and pointed out that MaaS could substitute private car usage for commuting trips.

A MaaS ecosystem is built on the interactions between users, the TSPs, a MaaS platform operator (MPO), public authorities, and other related partners [1]. The users provide trip requests, including a pick-up point, drop-off point, departure and/or arrival time interval, and mobility preferences. The TSPs include (1) PuT providers (i.e., buses and trains) operated by fixed routes, predefined service frequency, and fares; (2) on-demand service providers (i.e., carsharing, bikesharing, ridesharing, ride-hailing, and demand-responsive service) operated by a fleet of vehicles, flexible operational plans, and fare policies. The MPO plays a role in connecting the TSPs and users, integrating different TSPs to design mobility options according to user preferences. From a modeling perspective, exploring the demand-supply interactions under the complex multimodal system and integration of MaaS requires a much higher level of detail than conventional travel demand models [1] and a holistic modeling framework to capture all the influential aspects of MaaS. Kamargianni et al. [12] proposed a conceptual framework integrating different TSPs within a central platform; however, their study did not point out the indicators that represent the interactions between users, TSPs, and an MPO.

MaaS impacts user behaviors and preferences by facilitating accessibility to different available mobility options [6]. 
Accessibility generally includes both physical and psychological indicators. The former may be referred to as the level of transport supply, including travel time (e.g., transfer time, waiting time, in-vehicle time, and access/egress time), travel distances, and costs to travel [13-17]. The latter reflects users' perception of safety, security, comfort, available information, and their perception of physical indicators by utilizing transport services $[15,18]$. Increased accessibility may lead to an increase in the total amount of user demands; however, it may also increase the operational costs of TSPs and users' travel costs. To support decision making and planning in a complex multimodal system, it is essential to understand the indicators that affect the demand-supply interactions. While some studies have focused on modeling the operation of integrated on-demand services with PuT services, a comprehensive understanding of the indicators and models used to model the demand-supply interactions has not yet been established in the literature. Consequently, this study focuses on exploring accessibility indicators that influence the interactions between users, TSPs, and an MPO to generate a conceptual framework for modeling these interactions in the MaaS context.

The remainder of this paper is organized as follows. Section 2 describes the methodology of the systematic literature review. Section 3 presents the key results of this systematic review. In this section, the results of reviewing accessibility indicators from (1) users' viewpoint; (2) TSPs' viewpoint; (3) MPO's viewpoint will be presented separately; and (4) we also illustrated the demand-supply interactions through identified indicators. In the final section, we discuss the main findings and offer critical directions for further studies.

\section{Methodology}

We only selected papers published in peer-reviewed journals indexed in the Scopus, Web of Science, and ScienceDirect, while limiting the search from 2014, which was the time MaaS emerged until August 2020. We only considered papers that considered: (1) multimodal integration, particularly the integration of on-demand services with PuT services, and (2) modeling the demand-supply interactions. Keywords were separately used for searching all relevant papers: "Mobility as a Service"; "MaaS"; "on-demand mobility"; "shared mobility"; "on-demand service"; "ondemand transport service"; "ride-hailing"; "ridesharing"; "multimodal transport"; and "integrated transport services."

The first search was conducted across keywords and identified a total of 1,940 papers in which 995,482 , and 503 papers were found from the sources of Scopus, Web of Science, and ScienceDirect, respectively. Duplicated papers from three search sources were identified using Mendeley, and 723 duplicated papers were removed. Following the initial search, most papers were eliminated by reviewing titles $(\mathrm{n}=1,026)$, predominantly for being unrelated to multimodal integration and MaaS. In the next step, we categorized the remaining 190 papers into $37,7,28,78$, and 40 papers related to the demand side, supply side, platform side, multimodal integration modeling part, and mixed part, respectively, and then conducted an abstract review of these articles.

After an abstract review, we rejected 110 papers. We rejected 15 papers on the demand side, predominantly for being unrelated to users' behaviors and preferences and removed four papers on the supply side regarding discussion papers. On the platform side, 12 papers regarding discussions and technological provisions were rejected. We removed 41 papers on the multimodal modeling part related to logistic delivery and a single transport service. On the mixed part, most papers focusing on discussions, challenges, and barriers were rejected, and only two remaining papers related to the demand side were selected for full-text review.

The remaining 80 papers were considered for full-text review. We removed seven papers related to literature review and non-descriptive statistics on the demand side, deleting two papers describing the roles of MPO in the MaaS ecosystem on the platform side. On the supply side, one study focusing on the operational costs of on-demand service in isolation was rejected. In the modeling part, 20 papers related to modeling independently the operation of on-demand services within a multimodal network were removed, while two papers were not available. A total of 50 papers were identified for analysis in this study. Figure 1 shows the identification process of relevant papers.

The user demands for MaaS mainly focused on user behaviors [5, 7, 8, 19, 68], user preferences [20-22], willingness to use [22-29], and willingness to pay [30-35]. The

$$
\begin{aligned}
& \begin{array}{l}
\text { Literature } \\
\text { review }
\end{array}\left\{\begin{array}{l}
\cdot \text { Total search: } \mathrm{n}=1,940 \text { papers } \\
\bullet 723 \text { duplicated papers removed }
\end{array}\right. \\
& \begin{array}{l}
\text { Title \& } \\
\text { abstract } \\
\text { review }
\end{array}\left\{\begin{array}{l}
\cdot \text { Total review: } \mathrm{n}=1,217 \text { papers } \\
\bullet 1,032 \text { papers excluded by title review } \\
\text { review }
\end{array}\right.
\end{aligned}
$$$$
\text { Full-text }\left\{\begin{array}{c}
\cdot \text { Total fulltext review: } \mathrm{n}=80 \text { papers } \\
\cdot \text { Demand side: } \mathrm{n}=24 \text { papers } \\
\cdot \text { Supply side: } \mathrm{n}=03 \text { papers } \\
\cdot \text { Platform side: } \mathrm{n}=16 \text { papers } \\
\cdot \text { Modeling part: } \mathrm{n}=37 \text { papers } \\
\cdot \text { Total excluded papers: } \mathrm{n}=30 \text { papers }
\end{array}\right.
$$

Inclusion $\{$. Total selected papers: $\mathrm{n}=50$

Fig. 1 The identification process of selecting papers 
supply side concentrated on service package creation [36] and pricing schemes [37]. The platform side focused on matching both users and vehicles, route planning [38-49], and the impact of MPO on users [50-52]. The modeling part focused on modeling the demand-supply interactions [48, 53-67].

\section{Results of Systematic Literature Review}

Figure 2 describes the interactions between the three stakeholders through physical and psychological accessibility indicators. The TSPs generally provide physical infrastructure, facilities, and services described as initial physical indicators based on user demands. Users' perceptions of safety, security, comfort, available information, and their perceptions of initial physical indicators are formed through utilizing transport infrastructure, facilities, and services. Users decide whether to utilize transport services at a later time based on their psychological evaluation of physical accessibility indicators. In MaaS, the MPO conducts operational plans (e.g., dispatching and relocating strategy with integrated PuT) to serve user requests. Further, the MPO makes agreements with TSPs who provide initial physical indicators to create service packages, pay-as-usage options, operational plans and information, fare, and ticket integrations to offer to users. New physical indicators reflecting travel time, waiting time, fares, transfer locations, service integration, flexibility, etc., will present services provided by the MOP. Similarly, users also evaluate new accessibility indicators to decide whether to use the MaaS service. In this scene, the provision of MPO may rely on a range of available TSPs and their operational plans.

However, users also give requests and preferences for new physical indicators. The MPO might adjust the design of service packages, mobility options, and operational plans to meet user's needs, which in turn require the existing TSPs to adjust their operational plans and/or provisions of supply. In this case, TSPs adjust their operational plans and service provisions as per the requirement of the MPO, which may impact the operation of existing TSPs and generate an optimal transport system.

\subsection{Demand-Side}

Several studies exploring the results of MaaS pilots (e.g., Ubigo and Whim) indicated that simplicity, ease of access, comfort, flexibility, travel time, and travel costs are primary indicators leading to changes in user behaviors [7, 28, 68]. Furthermore, users' attitudes toward willingness to share and multimodal mobility are important indicators of the likelihood of using MaaS [20, 23-28]. Moreover, the pricing schemes and amount of travel distances and/or hours predefined for each transport service influence user preferences for MaaS packages [20, 21].

Further, several studies developed logit models to explore the willingness to pay (WTP) for different MaaS packages, showing that travel cost, travel time, and waiting time are important indicators affecting the WTP [31-35]. Moreover, the user preference for transport services in MaaS packages is another important indicator of WTP. Particularly, PuT services have significantly higher WTP than current market values, while bike sharing, car sharing, and taxi are significantly lower [33, 35]. Feneri et al. [21] studied the impacts of MaaS on mode choice behaviors and indicated that monthly fees and discounts impacted the tendency to use a specific mode included in the MaaS packages. Travel time, access time, waiting time, number of transfers, and fare schemes are key indicators that impact users' mode choices [41, 47, 57]. In addition, schedule delays and transfer penalties [67], available bikes or parking [45, 67], and road pricing scheme [55] are important indicators that impact user behaviors.

From a modeling perspective, Narayan et al. developed an agent-based model (ABM) considering total travel time (walking time, waiting time, and in-vehicle travel time), fare, travel distance, and number of transfers to model multimodal route choices; however, the model could not consider the influence of user preferences on mobility options [60]. In their study, the
Fig. 2 The interactions among the three stakeholders under impacts of physical/psychological indicators

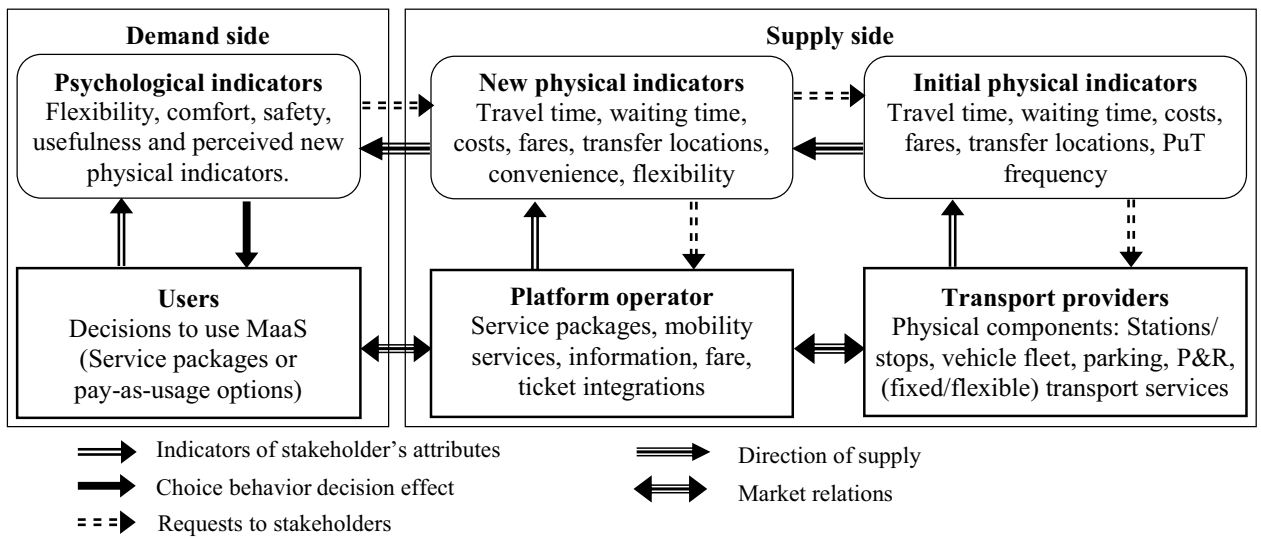


user demands were adjusted by changes in travel time, waiting time, fare policies, and operational plans through iterations implemented in the ABM. Furthermore, Liu et al. [48] considered the impact of waiting time on the choices of bikesharing and ridesharing to public transport stations. The studies by Wen et al. [53] and Printo et al. [62] improved the simulation models and considered the assumptions of user preferences for estimating travel demand in the multimodal context, but these analyses focused on the operation of autonomous vehicles (AVs).

In summary, user demands toward MaaS are impacted by both psychological and physical accessibility indicators. The former mainly related to simplicity, ease of access, comfort, flexibility, perceived travel time, travel costs, and users' willingness to share. In addition, user preferences for different transport services integrated in service packages also affect the likelihood of using MaaS. The latter primarily focused on travel time, access time, waiting time, number of transfers, and fare schemes.

\subsection{Supply-Side}

\subsubsection{Transport Service Providers}

From a modeling perspective, the TSPs considered the vehicle fleet size, transfer locations, fares, and operational costs of shared mobility services and the service frequency and fares of PuT services in their operational processes (see Table 1). Wen et al. [53] identified the vehicle fleet, vehicle capacity, operational policy, and fare policy for AVs based on user demands. Similarly, Narayan et al. [60] modeled the interactions between demands and supplies to determine fleet size, fare, and the level of service (waiting time and travel time) for the operation of ridesharing service. Moreover, several studies considered the transfer locations [ $[42,48$, 55], and unavailable bike and parking spots [63] to model the operational plans of the TSPs.

Price is an important indicator of TSPs. Wischik [37] determined the price of ridesharing based on user demands and PuT fare. In addition, Wen el al.[53] applied the fare, including base fare, per-unit-time fare, per-unit-distance fare, discount for sharing, and transferring for modeling the operation of AVs, while other studies considered fare as cost per unit distance or time $[42,54,56,60,62,67,70]$. Furthermore, additional road pricing was considered by Salazar et al. [55] in modeling the assignment of user requests to mobility options. The operational costs of the TSPs are modelled by total travel time [47, 60, 62], and travel distance $[42,62]$ as well as generalized costs (time, distance, maintenance, energy costs and fare) $[48,53-55,66]$.

On the contrary, some studies considered the perspective of service providers, particularly drivers' perspectives toward detour constraint (maximum distance and/or time) and maximum waiting time $[40,44,54-56,62,69]$ as well as expectations for perceived benefits $[39,64]$ to describe the availability of shared mobility services $[39,40,44,54-56$, $62,64,69]$.

\subsubsection{MaaS Platform Operator}

A primary operational task of the MPO is to match users' requests to available service providers, which are either ondemand service, PuT services, or an integration of both services through vehicle dispatching, idle vehicle relocation, and route planning process. The modeling objectives of the MPO are described in Table 2. The dispatching processes considered user's travel time and driver's detour time and waiting time to provide a journey with minimizing total travel time for both user and driver [38, 40, 41, 44, 60, 61, 63, 69], and maximizing the matched users [43, 46, 47, 67]. Furthermore, several studies proposed dispatching models to minimize the operational costs of shared mobility services $[45,56,62]$.

Moreover, Posada et al. [42] developed mixed integer linear programs aimed at minimizing the operational cost of the demand responsive service and the usage cost of PuT services. Chen et al. [66] used the mixed-integer optimization problem to minimize the total travel distance (PuT and e-hailing vehicles) and the total e-hailing fleet size. Furthermore, Salazar et al. [55] proposed a linear optimization model considering travel time, waiting time, capacity, and operational costs of AVs to maximize social welfare in terms of users' travel time together with the operational costs of available service providers. Djavadian and Chow [64] proposed a non-myopic dynamic dial-a-ride model considering
Table 1 Supply indicators accounted for in modeling

\begin{tabular}{ll}
\hline Supply-side indicators & References \\
\hline Physical indicators & \\
Fares, fleet sizes, capacities, and operational plans & {$[48,53,54,60]$} \\
Fleet size, capacity, PuT frequency, and transferring location & {$[40,42,43,55,59,62,66]$} \\
Available bikes, parking spots & {$[40,63,67]$} \\
Psychological indicators (Drivers) & \\
Detour constraints, waiting time & {$[40,44,54-56,62,69]$} \\
Detour constraints, waiting time, perceived profits & {$[39,64]$} \\
\hline
\end{tabular}


Table 2 Modeling objectives of platform operation

\begin{tabular}{ll}
\hline Objectives of Modeling & References \\
\hline Minimize travel time for both users and drivers & {$[38,40,41,44,60,61,63,69]$} \\
Minimize users' travel time and maximize drivers' matching rate & {$[43,46,47,67]$} \\
Minimize users' travel time and providers' operational costs & {$[39,42,45,48,49,56,62,66]$} \\
Maximize social welfare for both users and drivers & {$[55,64]$}
\end{tabular}

dynamic operational policies, such as dispatching, fare pricing, operational costs, to establish a generalized cost function for users and a consumer surplus function for ondemand service providers. In their study, maximum social welfare was obtained when the average consumer surplus of users was equal to the average profit of providers.

However, the MPO optimized the operational parameters of the TSPs in terms of total travel time, waiting time, vehicle fleet size, pricing schemes, waiting time, and number of transfer locations corresponding to demands [39, 44, 45, 49, $61,62,64,66,71]$. In contrast, Ma et al. [45] showed that a higher frequency of PuT can impact the performance of ridesharing platform, such as reducing users' waiting time while increasing the share of ridesharing trips for ridesharing platform.

\subsection{Modeling Interactions Between Demand- Supply}

To capture the interactions between users and TSPs, Wen et al. [53] proposed an ABM in the context of integrated AVs and PuT systems. In their study, the TSPs offer operational and fare policy, vehicle fleet, vehicle capacity reflecting in waiting time, travel time, detour factor (defined as the ratio of actual in-vehicle travel time with ridesharing to the shortest travel time without ridesharing), and travel cost. The demand-supply interactions are modeled by the waiting time and detour factor. In particular, the users' travel mode choices are affected by the waiting time and detour factor, which are changed by iterative simulation in the ABM, which in turn influence the supply parameters of AV services. Furthermore, the dynamic demand-supply interactions in a multimodal context are impacted by the various fleet sizes, number of transfers, fare, travel time, and waiting time $[54,57,60,66]$. Moreover, the study by Pinto et al. [62] using an ABM and Becker et al. [65] using MATSim to simulate the demand-supply interactions showed that travel time, travel cost, and PuT frequency are primary indicators. However, these studies are limited to the operation of an AV fleet and lack dynamic pricing for AVs as well. In addition, $\mathrm{Li}$ et al. [58] proposed an activity-based dynamic user equilibrium model to model the demand-supply interactions of free-floating shared cars and showed that demands of shared cars depend on the availability and the rental-parking price of free floating shared cars at a location at a certain time interval. Furthermore, Wischik [37] considered the demand-supply interactions based on the price of ridesharing and PuT fare. Pentelidis et al. [51] presented cost allocations and pricing of services between a public MPO and existing TSPs based on modeling the interactions among user route choice decisions and provider operational decisions.

The abovementioned models mainly considered physical accessibility indicators, including travel time, travel cost, and fare, to describe the interactions between user demand and TSPs. Another limitation of existing models is the lack of consideration of dynamic pricing (e.g., surge pricing) scheme, which is a key operational parameter of on-demand services. Egan and Jakob [72] represented the interactions among users and on-demand service providers through maximum price, waiting time, and desired pick-up time intervals. Users make decisions on either accepting or rejecting journeys offered by providers according to their preferences for maximum price, maximum waiting time, and departure time intervals, while service providers aim to jointly optimize the scheduling, routing, and pricing to maximize profits; however, this study is unrelated to multimodal integration and the MaaS context.

Furthermore, the MPO captured user needs and preferences for travel modes and service features to develop MaaS plans [50], although there were few models considering the assumptions of user preferences for different available mobility services to estimate user demand in a multimodal context [53,62]. There is a limitation in the integration of psychological indicators into modeling the interactions in existing studies, especially considering that users' willingness to share is a major limitation in modeling ridesharing and/or on-demand services. Moreover, the existing models focused on modeling and matching a single request to available mobility options. There is a lack of studies accounting for the interactions between users who choose monthly service packages and other service providers.

Furthermore, the reviewed models simulating the platform operation of on-demand services can establish and assign trip requests to other TSPs, such as PuT services and bike-sharing service although the TSPs are independently operated and not yet integrated into a single MPO. As a result, the existing models focus on the objectives of minimizing travel cost and/or travel time or maximizing the benefits of on-demand service [38-49, 55, 56, 60-63, 66, 67, 
69]. Therefore, a gap found in the literature is identified as a lack of studies accounting for the efficiency of both ondemand services and PuT services.

In addition, Djavadian and Chow [64] proposed an ABM to simulate a two-sided market where the operational policy is a function of user demand, and user costs are a function of the operational policy and network. Users are impacted by travel time (waiting time and in-vehicle time), schedule delay, and fare price. Drivers may decide whether to participate in service provision based on their expected profit threshold and the probability of getting a passenger. The platform is represented by operational policies and infrastructure network and is modeled in terms of maximizing the total welfare of both users and operators. The study showed that fare price and drivers' profit threshold significantly affected fleet size, which in turn impacts the performance of on-demand services, taxi demand, and total consumer surplus of users. Similarly, several studies also considered drivers' perspectives toward detour constraints (maximum distance and/or time) and maximum waiting time [40, 44, 54-56, 62, 69]. However, these studies overlooked the decisions of other TSPs, such as bike-sharing providers and shared car providers on providing available vehicles, which became another gap in the existing models.

\section{Conclusions and Discussions}

This study aimed to identify psychological and physical accessibility indicators to describe the demand-supply interactions in multimodal and MaaS contexts, and to point out limitations in integrating these indicators into modeling the interactions among users, TSPs, and an MPO. Following this literature review, the physical accessibility indicators, such as waiting time, travel time, travel cost, and fare price are mainly applied for modeling the demand-supply interactions. In addition, there are some gaps in modeling the interactions as follows:

First, a limitation found in the literature is the lack of models integrating psychological accessibility indicators for quantifying the demand-supply interactions, except for Wen et al. [53] and Pinto et al. [62] considered the assumptions of user preferences for AVs. In MaaS, use-oriented service provision needs to reflect user needs and preferences for travel modes and service attributes; thus, considering psychological indicators into models could comprehensively establish the interactions between users and service providers. Furthermore, considering psychological indicators could make MaaS more attractive and accessible to users.

Second, another limitation of existing models is the consideration of dynamic pricing for modeling the interactions. The dynamic price is commonly adjusted by the demand/ supply ratio and/or the available vehicle fleet size in the network [73]. Particularly, service providers set higher prices when user demand is higher than the amount of available service providers, which leads to a reduction in user demand and attracts more drivers simultaneously and vice versa. Overlooking dynamic pricing might influence the choice of alternative mobility services under multimodal systems, modeling the demand-supply interactions and the performance of an MPO.

Third, a gap found in the literature is to model the interactions between monthly users and/or service packages to TSPs. The monthly service packages might be identified by a fixed amount of travel time/distances and transport modes; therefore, the MPO can determine users' journeys in advance. Given a set of known user demands, the MPO can find optimal dispatching and alternative mobility options to meet user demands. In this scenario, the demand-supply interactions could be changed.

Fourth, another gap found in the literature is to account for the efficiency of transport systems. Since the TSPs are current-independent operations, modeling the platform operation aims to optimize a single transport service instead of joint optimization for transport systems. Considering this issue could help transport providers and planners obtain the target of transport system, such as maximizing operators' profits, minimizing operators' operational costs, and minimizing users' travel time and travel costs.

Finally, a gap of models that consider the perspectives of the TSPs in the modeling platform operation. In addition to considering drivers' decisions, it is necessary to consider the decisions of other TSPs when the MPO designs service packages and mobility options based on the users' preferences and available services. This could not be a major problem for PuT services because the PuT services operate with fixed schedules and routes; however, it becomes a considerable issue for other services, such as bike-sharing and car-sharing when the number of available vehicles is limited.

Further studies need to address the five limitations found in this study and generate a conceptual framework for modeling the interactions among users, TSPs and MPO in further work.

Acknowledgments The authors are thankful to the Tokyo Human Resources Fund for City Diplomacy for the research fund. The authors would like to thank the anonymous reviewers for their comments, which significantly improved this paper.

Open Access This article is licensed under a Creative Commons Attribution 4.0 International License, which permits use, sharing, adaptation, distribution and reproduction in any medium or format, as long as you give appropriate credit to the original author(s) and the source, provide a link to the Creative Commons licence, and indicate if changes were made. The images or other third party material in this article are included in the article's Creative Commons licence, unless indicated otherwise in a credit line to the material. If material is not included in the article's Creative Commons licence and your intended use is not permitted by statutory regulation or exceeds the permitted use, you will 
need to obtain permission directly from the copyright holder. To view a copy of this licence, visit http://creativecommons.org/licenses/by/4.0/.

\section{References}

1. Jittrapirom, P., Narayan, J., Feneri, A.-M., González, M.J.A., Caiati, V., Ebrahimigharehbaghi, S.: Mobility as a Service: A Critical Review of Definitions, Assessments of Schemes, and Key Challenges. Urban Planning 2(2), 13 (2017)

2. Lyons, G., Hammond, P., Mackay, K.: The importance of user perspective in the evolution of MaaS. Transportation Research Part A: Policy and Practice 121(January), 22-36 (2019)

3. Utriainen, R., Pöllänen, M.: Review on mobility as a service in scientific publications. Res. Transp. Bus. Manag. 27(March), $1-9$ (2018)

4. Karlsson, M., Sochor, J., Aapaoja, A., Eckhardt, J., König, D.: Impact Assessment - Deliverable $\mathrm{Nr}$ 4: MAASiFiE project funded by CEDR. Conference of European Directors of Roads (CEDR) (2017)

5. Karlsson, I.C.M., Sochor, J., Strömberg, H.: Developing the 'Service' in Mobility as a Service: Experiences from a Field Trial of an Innovative Travel Brokerage. Transportation Research Procedia 14, 3265-3273 (2016)

6. Durand, A., Harms, L., Hoogendoorn-lanser, S., Zijlstra, T.: Mobility-as-a-Service and changes in travel preferences and travel behaviour : a literature review (2018)

7. Sochor, J., Karlsson, I.C.M.A., Strömberg, H.: Trying out mobility as a service: Experiences from a field trial and implications for understanding demand. Transp. Res. Rec. 2542(2542), 57-64 (2016)

8. Strömberg, H., Karlsson, I.C.M., Sochor, J.: Inviting travelers to the smorgasbord of sustainable urban transport: evidence from a MaaS field trial. Transportation 45(6), 1655-1670 (2018)

9. smile mobility, "http://smile-einfachmobil.at/pilotbetrieb_en. html," smile mobility@ 2015. [Online]. Available: http://smileeinfachmobil.at/pilotbetrieb_en.html. [Accessed: 23 May 2020]. (2015)

10. Hartikainen, A, et al.: "Whim impact: Insights from the world's first Mobility-as-a-Service (MaaS) system," (2019)

11. Storme, T., De Vos, J., De Paepe, L., Witlox, F.: "Limitations to the car-substitution effect of MaaS. Findings from a Belgian pilot study," Transportation Research Part A: Policy and Practice, 131, 196-205 (2020)

12. Kamargianni M., Yfantis L., Muscat J., Azevedo C. L., Ben-akiva M.: "Incorporating the Mobility As a Service concept into transport modelling and simulation framework," in The 98th annual meeting of the Transportation Research Board, Washington, DC., 1-6. (2019)

13. Litman, T.: "Evaluating Accessibility for Transportation Planning: Measuring People's Ability to Reach Desired Goods and Activities," Transportation Research, 62, (2008)

14. Páez, A., Scott, D.M., Morency, C.: Measuring accessibility: Positive and normative implementations of various accessibility indicators. J. Transp. Geogr. 25, 141-153 (2012)

15. Geurs, K.T., van Wee, B.: Accessibility evaluation of land-use and transport strategies: Review and research directions. J. Transp. Geogr. 12(2), 127-140 (2004)

16. Saif, M.A., Zefreh, M.M., Torok, A.: Public transport accessibility: A literature review. Period. Polytech. Transp. Eng. 47(1), 36-43 (2018)

17. Kumar, P.: Multimodal Accessibility Indicators in GIS (2011)
18. Lättman, K., Friman, M., Olsson, L.E.: Perceived accessibility of public transport as a potential indicator of social inclusion. Social Inclusion 4(3), 36-45 (2016)

19. Sochor, J., Strömberg, H., Karlsson, I.C.M.: Implementing mobility as a service: Challenges in integrating user, commercial, and societal perspectives. Transp. Res. Rec. 2536(2536), 1-9 (2015)

20. Caiati, V., Rasouli, S., Timmermans, H.: "Bundling, pricing schemes and extra features preferences for mobility as a service: Sequential portfolio choice experiment," Transportation Research Part A: Policy and Practice, 131, 123-148 (2020)

21. Feneri, A. M., Rasouli, S., Timmermans, H. J. P.: "Modeling the effect of Mobility-as-a-Service on mode choice decisions," Transportation Letters, 1-8 (2020).

22. Vij, A., Ryan, S., Sampson, S., Harris, S.: "Consumer preferences for Mobility-as-a-Service (MaaS) in Australia," Transportation Research Part C: Emerging Technologies, 117, 102699 (2020)

23. Ye, J., Zheng, J., Yi, F.: "A study on users' willingness to accept mobility as a service based on UTAUT model," Technological Forecasting and Social Change, 157, 120066 (2020)

24. Alonso-González, M. J., Hoogendoorn-Lanser, S., van Oort, N., Cats, O., Hoogendoorn, S.: "Drivers and barriers in adopting Mobility as a Service (MaaS) - A latent class cluster analysis of attitudes," Transportation Research Part A: Policy and Practice, 132 378-401 (2020)

25. Zijlstra, T., Durand, A., Hoogendoorn-Lanser, S., Harms, L.: Early adopters of Mobility-as-a-Service in the Netherlands. Transp. Policy 97, 197-209 (2020)

26. Monzon, A., Lopez-Carreiro, I., Lopez, E.: "Evaluating citizens' willingness to uptake a MaaS tool for metropolitan multimodal trips," in 5th IEEE International Smart Cities Conference, ISC2 2019, 258-261 (2019)

27. Schikofsky, J., Dannewald, T., Kowald, M.: "Exploring motivational mechanisms behind the intention to adopt mobility as a service (MaaS): Insights from Germany," Transportation Research Part A: Policy and Practice, 131, 296-312 (2020)

28. Fioreze, T., de Gruijter, M., Geurs, K.: On the likelihood of using Mobility-as-a-Service: A case study on innovative mobility services among residents in the Netherlands. Case Studies on Transport Policy 7(4), 790-801 (2019)

29. Casadó, R. G., Golightly, D., Laing, K., Palacin, R., Todd, L.: "Children, Young people and Mobility as a Service: Opportunities and barriers for future mobility," Transportation Research Interdisciplinary Perspectives, 4, 100107 (2020)

30. Mulley, C. et al.: "Mobility as a service in community transport in Australia: Can it provide a sustainable future?," Transportation Research Part A: Policy and Practice, 131, 107-122 (2019)

31. Ho, C.Q., Hensher, D.A., Mulley, C., Wong, Y.Z.: Potential uptake and willingness-to-pay for Mobility as a Service (MaaS): A stated choice study. Transportation Research Part A: Policy and Practice 117(August), 302-318 (2018)

32. Liljamo, T., Liimatainen, H., Pöllänen, M., Utriainen, R.: People's current mobility costs and willingness to pay for Mobility as a Service offerings. Transportation Research Part A: Policy and Practice 136(February), 99-119 (2020)

33. Guidon, S., Wicki, M., Bernauer, T., Axhausen, K.: “Transportation service bundling - For whose benefit? Consumer valuation of pure bundling in the passenger transportation market," Transportation Research Part A: Policy and Practice, 131, 91-106 (2019)

34. Ho, C. Q., Mulley, C., Hensher, D. A.: "Public preferences for mobility as a service: Insights from stated preference surveys," Transportation Research Part A: Policy and Practice, 131, 70-90 (2020)

35. Ratilainen, H.: "Exploring consumer preferences for Maas Subcription packages using a stated choice experiment.", 127 (2017) 
36. Esztergár-Kiss, D., Kerényi, T.: "Creation of mobility packages based on the MaaS concept," Travel Behaviour and Society, 1-11 (2019)

37. Wischik, D.: "The price of choice: Models, paradoxes, and inference for "mobility as a service,"' 2018 56th Annual Allerton Conference on Communication, Control, and Computing, Allerton 2018, 604-610 (2019)

38. Varone, S., Aissat, K.: "Multi-modal transportation with public transport and ride-sharing: Multi-modal transportation using a path-based method," ICEIS 2015 - 17th International Conference on Enterprise Information Systems, Proceedings, 1, 479-486 (2015)

39. Fahnenschreiber, S., Gündling, F., Keyhani, M.H., Schnee, M.: A Multi-modal Routing Approach Combining Dynamic Ridesharing and Public Transport. Transportation Research Procedia 13, 176-183 (2016)

40. Luo, Q., Dou, X., Di, X., Hampshire, R. C.: "Multimodal Connections between Dockless Bikesharing and Ride-Hailing: An Empirical Study in New York City," IEEE Conference on Intelligent Transportation Systems, Proceedings, ITSC, 2256-2261 (2018)

41. Jamal, J., Montemanni, R., Huber, D., Derboni, M., Rizzoli, A. E.: "A Multi-Modal and Multi-Objective Journey Planner for Integrating Carpooling and Public Transport," Journal of Traffic and Logistics Engineering, 5 (2017)

42. Posada, M., Andersson, H., Häll, C.H.: The integrated dial-aride problem with timetabled fixed route service. Public Transport 9(1-2), 217-241 (2017)

43. Ma, T.: "On-demand Dynamic Bi- / multi-modal Ride- sharing using Optimal Passenger-vehicle Assignments," (2017)

44. Levin, M. W., Odell, M., Samarasena, S., Schwartz, A.: "A linear program for optimal integration of shared autonomous vehicles with public transit," Transportation Research Part C: Emerging Technologies, 109, 267-288 (2019)

45. Ma, T.Y., Rasulkhani, S., Chow, J.Y.J., Klein, S.: A dynamic ridesharing dispatch and idle vehicle repositioning strategy with integrated transit transfers. Transportation Research Part E: Logistics and Transportation Review 128(June), 417-442 (2019)

46. Stiglic, M., Agatz, N., Savelsbergh, M., Gradisar, M.: Enhancing urban mobility: Integrating ride-sharing and public transit. Comput. Oper. Res. 90, 12-21 (2018)

47. Cangialosi, E., Di Febbraro, A., Sacco, N.: Designing a multimodal generalised ride sharing system. IET Intel. Transport Syst. 10(4), 227-236 (2016)

48. Liu, L., Sun, L., Chen, Y., Ma, X.: Optimizing fleet size and scheduling of feeder transit services considering the influence of bike-sharing systems. J. Clean. Prod. 236, 117550 (2019)

49. Liang, X., de Correia, G. H. A., van Arem, B.: "Optimizing the service area and trip selection of an electric automated taxi system used for the last mile of train trips," Transportation Research Part E: Logistics and Transportation Review, 93 115-129 (2016)

50. Arnaoutaki, K., Magoutas, B., Bothos, E., Mentzas, G.: A hybrid knowledge-based recommender for Mobility-as-a-Service. Science and Technology Publications 1, 95-103 (2019)

51. Pantelidis, T.P., Chow, J.Y.J., Rasulkhani, S.: A many-to-many assignment game and stable outcome algorithm to evaluate collaborative mobility-as-a-service platforms. Transportation Research Part B: Methodological 140, 79-100 (2020)

52. Beheshtian, A. et al.: "Bringing the efficiency of electricity market mechanisms to multimodal mobility across congested transportation systems," Transportation Research Part A: Policy and Practice, 131, 58-69 (2020)
53. Wen, J., Chen, Y. X., Nassir, N., Zhao, J.: “Transit-oriented autonomous vehicle operation with integrated demand-supply interaction," Transportation Research Part C: Emerging Technologies, 97, 216-234 (2018)

54. Shen, Y., Zhang, H., Zhao, J.: Integrating shared autonomous vehicle in public transportation system: A supply-side simulation of the first-mile service in Singapore. Transportation Research Part A: Policy and Practice 113(Apr), 125-136 (2018)

55. Salazar, M., Rossi, F., Schiffer, M., Onder, C. H., Pavone, M.: "On the Interaction between Autonomous Mobility-on-Demand and Public Transportation Systems," IEEE Conference on Intelligent Transportation Systems, Proceedings, ITSC, 2262-2269 (2018)

56. Masoud, N., Nam, D., Yu, J., Jayakrishnan, R.: Promoting peerto-peer ridesharing services as transit system feeders. Transp. Res. Rec. 2650(1), 74-83 (2017)

57. de Pinto H. K. R. F., Hyland, M. F., Verbas, İ. Ö., Mahmassani, H. S., Board, T. R.: "Integrated Mode Choice and Dynamic Traveler Assignment-Simulation Framework to Assess the Impact of a Suburban First-Mile Shared Autonomous Vehicle Fleet Service on Transit Demand," Transportation Research Record: Journal of the Transportation Research Board, 9 (2018)

58. Li, Q., Liao, F., Timmermans, H.J.P., Huang, H., Zhou, J.: Incorporating free-floating car-sharing into an activity-based dynamic user equilibrium model: A demand-side model. Transportation Research Part B: Methodological 107, 102-123 (2018)

59. Vakayil, A., Gruel, V., Samaranayake, S.: "Integrating SharedVehicle Mobility-on-Demand Systems with Public Transit," Conference Transportation Research Board 96th Annual Meeting, 17-05439, (2017)

60. Narayan, J., Cats, O., van Oort, N., Hoogendoorn, S.: "Integrated route choice and assignment model for fixed and flexible public transport systems," Transportation Research Part C: Emerging Technologies, 115, 102631 (2020)

61. Wright, S., Nelson, J. D., Cottrill, C. D.: "MaaS for the suburban market: Incorporating carpooling in the mix," Transportation Research Part A: Policy and Practice, 131, 206-218 (2019)

62. Pinto, H.K.R.F., Hyland, M.F., Mahmassani, H.S., Verbas, I.Ö.: Joint design of multimodal transit networks and shared autonomous mobility fleets. Transportation Research Procedia 38(2017), 98-118 (2018)

63. Hebenstreit, C., Fellendorf, M.: A dynamic bike sharing module for agent-based transport simulation, within multimodal context. Procedia Computer Science 130, 65-72 (2018)

64. Djavadian, S., Chow, J.Y.J.: An agent-based day-to-day adjustment process for modeling 'Mobility as a Service' with a two-sided flexible transport market. Transportation Research Part B: Methodological 104(October), 36-57 (2017)

65. Becker, H., Balac, M., Ciari, F., Axhausen, K. W.: "Assessing the welfare impacts of Shared Mobility and Mobility as a Service (MaaS)," Transportation Research Part A: Policy and Practice, 131, 228-243 (2019)

66. Chen P. W., Nie, Y. M.: "Connecting e-hailing to mass transit platform: Analysis of relative spatial position," Transportation Research Part C: Emerging Technologies, 77, 444-461 (2017)

67. Nam, D., Yang, D., An, S., Yu, J.G., Jayakrishnan, R., Masoud, N.: Designing a Transit-Feeder System using Multiple Sustainable Modes: Peer-to-Peer (P2P) Ridesharing, Bike Sharing, and Walking. Transp. Res. Rec. 2672(8), 754-763 (2018)

68. Harms, L., Durand, A., Hoogendoorn-Lanser, S.: "Potential for mode shifts due to Mobility-as-a-Service : results from the Netherlands Mobility Panel," (2018) 
69. Aissat, K., Varone, S.: "Real-time ride-sharing substitution service in multi-modal public transport using buckets," Advances in Intelligent Systems and Computing, vol. 360, 521 (2015)

70. Li, X., Wei, M., Hu, J., Yuan, Y., Jiang, H.: "An Agent-Based Model for Dispatching Real-Time Demand-Responsive Feeder Bus," Mathematical Problems in Engineering, (2018)

71. Chen, S., Wang, H., Meng, Q.: Solving the first-mile ridesharing problem using autonomous vehicles. Computer-Aided Civil and Infrastructure Engineering 35(1), 45-60 (2020)

72. Egan, M., Jakob, M.: Market mechanism design for profitable on-demand transport services. Transportation Research Part B: Methodological 89, 178-195 (2016)

73. Novak, K. M., Kalanick, T. C.: "System and method for dynamically adjusting prices for services," US Patent Application Publication, 1(19), (2013)

Publisher's Note Springer Nature remains neutral with regard to jurisdictional claims in published maps and institutional affiliations.

Hoang Duy PHAM received an MS.c degree at Technische Universität Darmstadt in 2017. He is currently a PhD student in the Department of Tourism Science at Tokyo Metropolitan University. His research interests lie within the areas of traffic and transport planning, shared mobility, and MaaS.

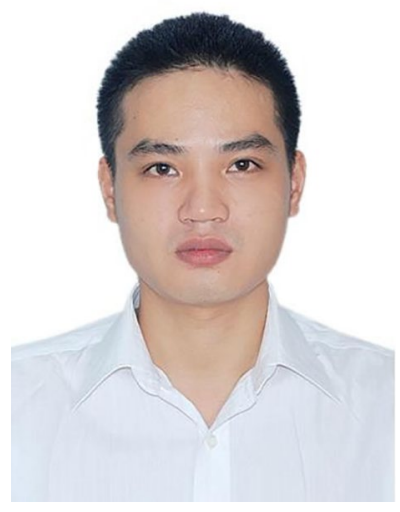

Tetsuo Shimizu is a professor at Tokyo Metropolitan University. He has researched ITS implementation processes as well as travel behavior under ITS services. His research interest also includes MaaS development for tourism promotion.

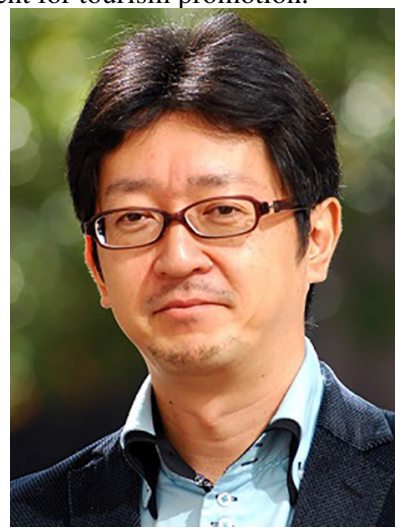

Truong Van NGUYEN (PhD) is a lecturer at University of Transport and Communication, Vietnam. His research interest includes modeling in transport, tourism, economy, and policy study. He is also interested in MaaS in transport and tourism.

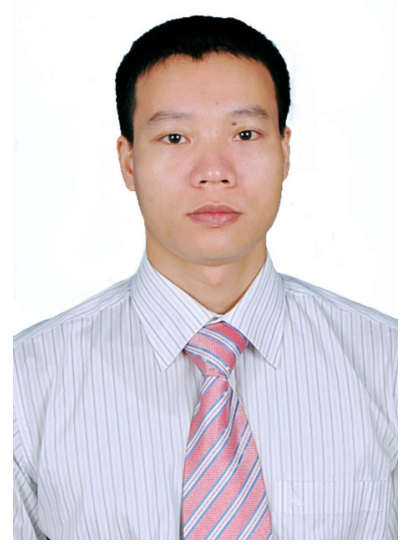

